\title{
Qualidade da Dieta Selecionada por Bovinos na Sub-Região da Nhecolândia, Pantanal ${ }^{1}$ Sandra Aparecida Santos ${ }^{2}$, Ciniro Costa ${ }^{3}$, Geraldo da Silva e Souza ${ }^{4}$, André Steffens Moraes ${ }^{5}$,
Mário De Beni Arrigoni ${ }^{3}$
}

\begin{abstract}
RESUMO - Objetivou-se com o estudo determinar o valor nutritivo da dieta selecionada por vacas de cria, numa área característica da sub-região da Nhecolândia, Pantanal, durante dois anos hidrológicos (outubro de 1997 a setembro de 1999). Mensalmente foram colhidas manualmente amostras das partes das principais forrageiras selecionadas por bovinos, identificadas por meio de observação direta, para análise de proteína bruta (PB), fibra em detergente neutro (FDN), fibra em detergente ácido (FDA) e lignina (LIG). A digestibilidade da matéria orgânica (DMO) da dieta foi avaliada em amostras fecais com o uso da espectrofotometria de reflectância no infravermelho proximal (NIRS). Houve efeito interativo de ano e época para todos os constituintes químicos analisados na dieta. O valor nutritivo da dieta selecionada por bovinos diminuiu no período de abril a junho, em ambos os anos estudados. As vacas apresentaram uma melhor condição corporal de setembro a março do ano hidrológico 1998/99, no qual a dieta apresentou valores médios de 60,4\% de digestibilidade, $10 \%$ de PB; 40,20\% de FDA; 71\% de FDN e 6,0\% de lignina, considerada adequada para obtenção de um desempenho reprodutivo satisfatório. Portanto, o valor nutritivo da dieta selecionada por bovinos na sub-região da Nhecolândia depende especialmente da intensidade e distribuição das chuvas, responsáveis pela maior ou menor presença de água nas unidades mais baixas, que possuem forrageiras de melhor qualidade.
\end{abstract}

Palavras-chave: condição corporal, desempenho reprodutivo, nutrição, pastagem nativa

\section{Quality of the Diet Selected by Cattle in the Nhecolândia Sub-Region, Pantanal}

\begin{abstract}
The objective of this study was to evaluate the nutritive value of the diet by cows grazing in natural pastures, in a typical area of Nhecolândia sub-region, Pantanal, during two hydrological years: from October 1997 to September 1999. Grazed forage species samples, representative of the animals' diet, were collected manually in each month. All forage samples were analyzed for crude protein (CP), acid detergent fiber (ADF), neutral detergent fiber (NDF), and lignin (LIG). Near infrared spectrofotometry (NIRS) was used to estimate the organic matter digestibility (\%) indirectly from fecal samples collected monthly. There was year vs season interaction for all chemical constituents. Cows showed better body score condition from September to March of 1998/99, when the diet had average levels of $60,4 \%, 10 \%, 40.20 \%, 71 \%$, and $6 \%$ for digestibility, CP, ADF, NDF and LIG, respectively. These levels appeared appropriate for meeting cow reproductive demands in the conditions of the studied area. Thus, the diet nutritive value selected by cattle is dependent on annual climatic conditions, especially the rainfall intensity and distribuiton, that cause more or less presence of water on the lowland, areas with more nutritive forage species.
\end{abstract}

Key Words: body condition, nutrition, reproductive performance, rangelands

\section{Introdução}

No Pantanal como nas demais regiões tropicais, a produtividade de bovinos criados extensivamente em pastagens nativas é baixa. Um dos principais fatores se deve à estacionalidade da produção das pastagens, agravada no Pantanal pelas inundações que dependendo da duração e intensidade, podem deixar submersas grande parte das principais unidades de paisagem usadas para pastejo (Pott, 1997). Além da variação temporal, os recursos forrageiros do Pantanal exibem extrema variação espacial. Segundo O'Reagain \& Schwartz (1995) esta variabilidade temporal e espacial é problemática para animais em pastejo cujas necessidades nutricionais são relativamente constantes. Inúmeros estudos têm mostrado que a dieta selecionada pelos animais apresenta qualidade superior ao pasto disponível (Sanches et al., 1993; Lima et al., 1998).

A capacidade de um animal crescer e se reproduzir é determinada principalmente por seu genótipo e pelo valor nutritivo da dieta. Para os grandes herbívoros

\footnotetext{
${ }^{1}$ Parte da tese de Doutorado apresentada à FMVZ-UNESP, Campus de Botucatu, SP. Parcialmente financiada pelo FUNDECT e PRODETAB.

${ }^{2}$ Pesquisadora da Embrapa Pantanal, Cx. Postal 109, 79320-900, Corumbá, MS. Bolsista do CNPq. E.mail: sasantos@cpap.embrapa.br 3 Professores da FMVZ-UNESP, Campus de Botucatu, SP. E.mail: secdmna@fca.unesp.br

${ }^{4}$ Pesquisador da Embrapa - Secretaria de Administração Estratégica, Brasília, DF. E.mail: geraldo@sede.embrapa.br

${ }^{5}$ Pesquisador da Embrapa Pantanal, Corumbá, MS. E.mail: andre@cpap.embrapa.br
} 
em pastejo, a dieta é o fator limitante para o seu desempenho, daí a importância de se conhecer o valor nutritivo da dieta e suas variações temporais e espaciais. A constituição química da forragem é refletida no consumo voluntário de alimentos, na digestibilidade, nos produtos finais da digestão, na eficiência de metabolismo, nas funções fisiológicas e resistência aos estresses ambientes (Vercoe, 1996), conseqüentemente, na produção animal. A qualidade da forragem tem sido considerada, nos últimos quarenta anos, como um produto de digestibilidade e consumo, dos quais o consumo é o processo mais importante (Fahey \& Hussein, 1999). Segundo Ulyatt $\&$ McNabb (1999), enquanto nas pastagens temperadas, o consumo voluntário é limitado pelo teor de energia, nas pastagens tropicais o consumo é limitado pelos teores de proteína e energia que são geralmente muito baixos e variáveis no decorrer do ano. Portanto, o conhecimento do valor nutritivo das forrageiras e da dieta é fundamental para a identificação do potencial das pastagens e dos períodos críticos de restrição alimentar e assim obter subsídios para manejo nutricional dos bovinos mantidos nestas condições.

O trabalho teve como objetivo avaliar a composição química e a digestibilidade mensal da dieta selecionada por vacas de cria, bem como verificar a influência da qualidade da dieta sobre a condição corporal das vacas de cria, durante dois anos hidrológicos, na subregião da Nhecolândia, Pantanal.

\section{Material e Métodos}

O estudo foi conduzido numa área de pastagem nativa (151 ha), localizada na sub-região da Nhecolândia, Pantanal, MS (lat. $19^{\circ} 04^{\prime}$ S, long. 56 $36^{\prime} \mathrm{W}$, alt. $98 \mathrm{~m}$ ). Na área foram mantidas 46 vacas de cria Nelore, numa lotação de 3,3 ha/cabeça, próxima da média tradicional, em pastejo contínuo. Com base na condição da pastagem estimada visualmente, a lotação foi considerada leve na maior parte do período, o que permitiu que os animais efetuassem pastejo seletivo.

A área de estudo apresenta as seguintes unidades de paisagem: floresta semidecídua (FS), regionalmente conhecida como mata; savana florestada, regionalmente conhecida como cerradão $(\mathrm{Ce})$ ou cerrado; savana arborizada, regionalmente conhecida como campo cerrado $(\mathrm{Cc})$; savana gramíneo-lenhosa, com predominância de Axonopus purpusii e
Andropogon spp., regionalmente conhecida como campo limpo (Ca); savana gramíneo-lenhosa, com predominância de Elyonurus muticus, regionalmente conhecida como caronal $(\mathrm{Cr})$; lagoas, regionalmente conhecidas como baías que podem ser permanentes $(\mathrm{Bp})$, pois possuem água durante o ano todo e temporárias $(\mathrm{Bt})$, pois secam em determinadas épocas do ano e vazantes/baixadas (Vb). Vazantes são vias de drenagem não seccionadas, formando extensas áreas periodicamente inundadas, enquanto baixadas referem-se aos pequenos desníveis do mesorelevo. A composição florística da área foi descrita detalhadamente por Santos et al. (2001b).

Cinco espécies forrageiras consideradas importantes na dieta, foram colhidas todos os meses, simulando o pastejo dos animais: A. purpusii, Mesosetum chaseae, Hymenachne amplexicaulis, Panicum laxum e Andropogon spp. O gênero Andropogon não foi considerado em nível de espécie, devido à dificuldade de identificação correta no período pós queima. As forrageiras colhidas foram pesadas frescas e em seguida, secas em estufa de circulação forçada de ar a $65^{\circ} \mathrm{C}$, para análises posteriores dos teores de matéria seca (MS); proteína bruta ( $\mathrm{PB})$ pelo método de Kjeldhal; fibra em detergente neutro (FDN), fibra em detergente ácido (FDA) e lignina, de acordo com Van Soest (1967).

A qualidade da dieta foi estimada pelo método utilizado por McInnis \& Vavra (1987). Foram calculadas as porcentagens de PB, FDA, FDN e lignina para a dieta identificada em cada lâmina fecal (Santos et al., 2001c), num total de 726 lâminas, segundo a equação:

$$
\mathrm{Ni}=\sum_{\mathrm{i}=1}^{\mathrm{n}} \underset{\mathrm{aijx}}{\mathrm{n}},
$$

em que: Ni é a participação do nutriente i na composição alimentar; aij é o conteúdo do nutriente i da espécie forrageira $\mathrm{j}$ e xj é a composição percentual em termos de peso seco da espécie forrageira j. Para as espécies forrageiras consumidas eventualmente, utilizou-se a composição média do constituinte analisado por época. Após o cálculo de Ni para cada lâmina, os dados foram agrupados por mês, época (quatro períodos trimestrais), ano (dois anos hidrológicos) e estado fisiológico das vacas (lactação, prenhes, vazias e novilhas). 
Para avaliar a digestibilidade da dieta, foi utilizada parte das amostras fecais frescas colhidas mensalmente para a análise microhistológica da dieta (Santos et al., 2002). Procurou-se obter um mínimo de cinco amostras de diferentes animais, que foram misturadas e refrigeradas. Em seguida, estas amostras foram pré-secas em estufa de circulação forçada de ar a $65^{\circ} \mathrm{C}$, desintegradas e embaladas em sacos de papel. Este material foi enviado para a Companhia de Irradiação de New Jersey, EUA, para a estimativa da digestibilidade da matéria orgânica (DMO) da dieta por meio da espectrofotometria de reflectância no infravermelho proximal (NIRS), com a utilização de curva espectral desenvolvida por Stuth et al. (1993).

Os componentes do comportamento de pastejo considerados foram tempo de ruminação (TR) e tempo de pastejo (TP), descritos por Santos et al. (2001a). A distância percorrida pelos animais foi avaliada no mapa, para o grupo com maior número de animais, calculando-se a distância entre os locais utilizados, considerando o caminho percorrido.

A estação de monta controlada ocorreu nos meses de dezembro a fevereiro, numa relação touro:vaca de 1:23. Foram efetuados exames andrológicos nos touros utilizados. O nascimento dos bezerros concentrou-se nos meses de outubro e novembro. Os animais receberam apenas sal comum durante o período de estudo, conforme prática de manejo ainda adotada pela grande maioria dos fazendeiros. Vacinação e everminação foram realizadas conforme manejo sanitário adotado na fazenda.

Os dados de precipitação foram fornecidos pela Estação Agroclimatológica de Nhumirim, da Embrapa Pantanal. Durante o período de estudo, foram efetuadas queimas localizadas na área, que consiste na queima dos sítios que apresentam predominância de espécies forrageiras cespitosas maduras ('macega'), geralmente presentes nas unidades de campo limpo com predominância de Andropogon spp e nas unidades de caronal com predominância de Elyonurus muticus ('capim carona').

As vacas foram pesadas mensalmente após jejum de uma noite. Devido à presença de vacas de diferentes tamanhos e estados fisiológicos, em cada pesagem foi avaliada a condição corporal mediante apreciação visual, utilizando uma escala de nove escores, desenvolvida por Nicholson \& Butterworth (1985) para gado zebuíno. Como os bezerros foram mantidos com a mãe até 10-12 meses de idade para avaliação da dieta de bezerros, o desempenho reprodutivo das vacas foi avaliado somente pela taxa de natalidade.

A porcentagem dos constituintes químicos da dieta (PB, FDA, FDN, LIG) foi analisada como um delineamento de parcelas subdivididas não balanceadas no tempo com o uso do PROC MIXED (SAS, 1999). Os efeitos principais das parcelas foram época, estado fisiológico das vacas e respectivas interações conforme modelo linear:

$y_{i j}=\mu+\alpha_{i}+\rho_{j}+(\alpha \rho)_{i j}+\theta_{i j k}+\delta_{l}+(\alpha \delta)_{i l}+(\delta \rho) j l+(\alpha \delta \rho)_{i j l}+\varepsilon_{i j l v}$ em que: i representa o estado fisiológico das vacas, $\mathrm{j}$ época do ano, 1 ano, $\mathrm{k}$ uma das repetições aninhadas na interação de $2^{\mathrm{a}}$ ordem dos fatores presentes nas comparações de parcelas e $\mathrm{v}$, uma das repetições aninhadas na interação de $3^{\mathrm{a}}$ ordem presente nas comparações envolvendo as subparcelas. As respostas da composição percentual de cada constituinte químico da dieta para os fatores época e ano foram avaliadas com o teste de Wald.

$\mathrm{O}$ grau de associação entre as variáveis $\mathrm{PB}$, FDA, FDN, LIG, digestibilidade (DMO), tempo de ruminação (TR), tempo de pastejo (TP), nível de precipitação (PPT) e distância percorrida diariamente (DIST) foi avaliado por meio do cálculo do coeficiente de correlação não paramétrico de Spearman. O efeito destas variáveis sobre o escore de condição corporal das vacas foi avaliado por meio da regressão não paramétrica utilizando os postos ('ranks') dos escores como função das variáveis analisadas (SAS, 1999).

\section{Resultados e Discussão}

Não foi observado efeito significativo $(\mathrm{P}>0,05)$ da interação do estado fisiológico das vacas com época e ano, bem como do estado fisiológico das vacas com nenhum dos constituintes químicos analisados. Portanto, os resultados foram considerados para o rebanho de vacas de cria como um todo.

Houve efeito interativo de ano e época $(\mathrm{P}<0,05)$ para todos os constituintes químicos analisados. Na Tabela 1 constam as médias estimadas dos quadrados mínimos de PB, FDA, FDN e LIG, expressos com base da matéria seca, de acordo com as diferentes épocas (períodos trimestrais) durante dois anos hidrológicos, com exceção do período de janeiro a março do ano de 1998/99, no qual as médias não foram estimáveis no contexto do modelo linear utilizado. Neste período, as médias observadas para PB,

R. Bras. Zootec., v.31, n.4, p.1663-1673, 2002 
Tabela 1 - Médias dos quadrados médios (Lsmeans) dos teores médios de proteína bruta (PB), fibra em detergente ácido (FDA), fibra em detergente neutro (FDN) e lignina (LIG) da dieta selecionada pelos animais nos diferentes períodos, durante dois anos hidrológicos

Table 1 - Least squares means (LSmeans \pm se) of the averages levels of crude protein (CP), acid detergent fiber (ADF), neutral detergent fiber (NDF) and lignin (LIG) of the diet selected by animals in different seasons, during two hydrologic years

\begin{tabular}{|c|c|c|c|c|}
\hline $\begin{array}{l}\text { Variáveis } \\
\text { Variables }\end{array}$ & $\begin{array}{l}\text { Out.-Dez. } \\
\text { Oct.-Dec. }\end{array}$ & $\begin{array}{c}\text { Jan.-Março } \\
\text { Jan.-March }\end{array}$ & $\begin{array}{l}\text { Abril-Junho } \\
\text { April-June }\end{array}$ & $\begin{array}{l}\text { Julho-Set. } \\
\text { July-Sept. }\end{array}$ \\
\hline $\begin{array}{l}\mathrm{PB}, \% \\
C P, \%\end{array}$ & & & & \\
\hline $\begin{array}{l}1997 / 98 \\
1998 / 99\end{array}$ & $\begin{array}{c}9,92 \pm 0,14^{\mathrm{cA}} \\
10,27 \pm 0,20^{\mathrm{cA}}\end{array}$ & $\begin{array}{c}10,36 \pm 0,16^{\mathrm{c}} \\
\text { Não estimável } \\
\text { inestimable }\end{array}$ & $\begin{array}{l}8,59 \pm 0,15^{\mathrm{aA}} \\
8,89 \pm 0,15^{\mathrm{aA}}\end{array}$ & $\begin{array}{l}9,14 \pm 0,19^{\mathrm{bA}} \\
9,42 \pm 0,17^{\mathrm{bA}}\end{array}$ \\
\hline $\begin{array}{l}\text { FDA, } \% \\
A D F, \%\end{array}$ & & & & \\
\hline $\begin{array}{l}1997 / 98 \\
1998 / 99\end{array}$ & $\begin{array}{l}40,61 \pm 0.20^{\mathrm{aA}} \\
40,20 \pm 0,28^{\mathrm{aA}}\end{array}$ & $\begin{array}{c}41,03 \pm 0,23^{\mathrm{a}} \\
\text { Não estimável } \\
\text { inestimable }\end{array}$ & $\begin{array}{l}43,56 \pm 0,22^{\mathrm{cB}} \\
41,93 \pm 0,21^{\mathrm{bA}}\end{array}$ & $\begin{array}{c}42,11 \pm 0,26^{\mathrm{bB}} \\
40,90 \pm 0,23 \mathrm{a}^{\mathrm{bA}}\end{array}$ \\
\hline $\begin{array}{l}\text { FDN, \% } \\
N D F, \%\end{array}$ & & & & \\
\hline $\begin{array}{l}1997 / 98 \\
1998 / 99\end{array}$ & $\begin{array}{l}72,66 \pm 0,23^{\mathrm{aB}} \\
70,96 \pm 0,34^{\mathrm{bA}}\end{array}$ & 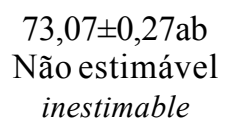 & $\begin{array}{l}75,21 \pm 0,26^{\mathrm{cB}} \\
72,06 \pm 0,26^{\mathrm{cA}}\end{array}$ & $\begin{array}{l}73,56 \pm 0,31^{\mathrm{bB}} \\
69,42 \pm 0,28^{\mathrm{aA}}\end{array}$ \\
\hline $\begin{array}{l}\text { LIG, \% } \\
\text { LIG, \% }\end{array}$ & & & & \\
\hline $\begin{array}{l}1997 / 98 \\
1998 / 99\end{array}$ & $\begin{array}{c}5,63 \pm 0,13^{\mathrm{aA}} \\
6,0 \pm 0,18^{\mathrm{aA}}\end{array}$ & $\begin{array}{c}6,35 \pm 0,15^{\mathrm{b}} \\
\text { Não estimável } \\
\text { inestimable }\end{array}$ & $\begin{array}{c}7,28 \pm 0,14 \mathrm{cA} \\
7,79 \pm 0,14 \mathrm{bB}\end{array}$ & $\begin{array}{l}6,83 \pm 0,17^{\mathrm{cA}} \\
7,84 \pm 0,15^{\mathrm{bB}}\end{array}$ \\
\hline
\end{tabular}

Médias, na linha, seguidas de letras minúsculas diferentes $(a<b<c)$ e médias, na coluna, seguidas de letras maiúsculas diferentes $(A<B)$ diferem estatisticamente pelo teste de Wald $(P<0,05)$.

Means, in a row, followed by different letters $(a<b<c)$ and means, in a column, followed by different capital letters $(A<B)$, differ statistically by Wald test ( $P<.05)$.

FDA, FDN e LIG foram 8,55; 41,42; 72,0 e 6,09\%, respectivamente.

Os teores médios estimados de $\mathrm{PB}$ foram mais baixos no período de abril a junho, que corresponde normalmente ao pico da cheia; porém, cheia parcial só ocorreu no ano de 1998/99 no mês de janeiro, ano considerado 'atípico'. Já os teores médios de PB mais elevados ocorreram no período de outubro a março no ano de 1997/98, que correspondeu ao período das chuvas, enquanto que no ano de 1998/99, valores médios mais elevados ocorreram no início das chuvas (outubro a dezembro). As mudanças na qualidade da dieta provavelmente estão associadas com a composição florística dos principais sítios utilizados para pastejo por bovinos e da dieta consumida (Santos et al., 2001c), variáveis em função das condições climáticas anuais.

Durante os meses avaliados, a proteína bruta média da dieta teve uma variação de 8,30 a 11,31\% (Figura 1), abaixo do requerimento de 12\%, nível considerado ideal para todos os propósitos de um rebanho de corte (Ulyatt, 1973 citado por Euclides,

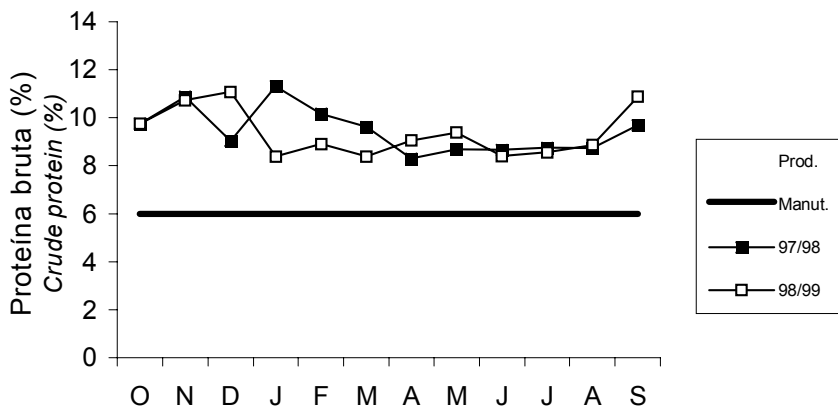

Meses

Months

Figura 1 - Níveis médios observados de proteína bruta na dieta de bovinos, durante dois anos hidrológicos na sub-região da Nhecolândia, Pantanal, comparados com os requerimentos de manutenção e produção

Figure 1 - Mean levels observed of crude protein of cattle diet, during two hydrologic years in Nhecolândia sub-region, Pantanal, compared with the demand of maintenance (Manut.) and production (Prod.). 
1995). Vale ressaltar que os valores de PB da dieta estiveram acima dos teores encontrados nas partes das folhas selecionadas das principais espécies que compõem o grupo principal da dieta (Figura 2), com exceção das espécies $H$. amplexicaulis e $P$. laxum, indicando que os animais, provavelmente, complementam a dieta com espécies de maior valor nutritivo, geralmente presentes nas áreas mais baixas do mesorelevo. Os teores de PB mais elevados observados para A. purpusii e Andropogon spp., especialmente nos meses de setembro a novembro, foram decorrentes da queima efetuada no início deste. Conforme Pott (1997), a queima promove a rebrota, que é mais rica em nutrientes e tem alta digestibilidade.

Em determinadas épocas do ano, a quantidade total de forrageiras nas pastagens pode ser escassa e os ruminantes são incapazes de colher alimento diário suficiente para atender sua taxa de consumo potencialmente alta (Duncan, 1983). Quando a disponibilidade de alimentos diminui, a qualidade da dieta também diminui devido ao acréscimo de itens alimentares de baixa qualidade. Portanto, dependendo da disponibilidade de forragem na pastagem, a qualidade da dieta também pode cair abaixo do valor de manutenção do peso corporal (cerca de $6 \%$ de $\mathrm{PB}$ ), pois nestes níveis de $\mathrm{PB}$, a atividade dos microorganismos do rúmen é reduzida (Euclides, 1995). No período estudado, os níveis de $\mathrm{PB}$ excederam às necessida-

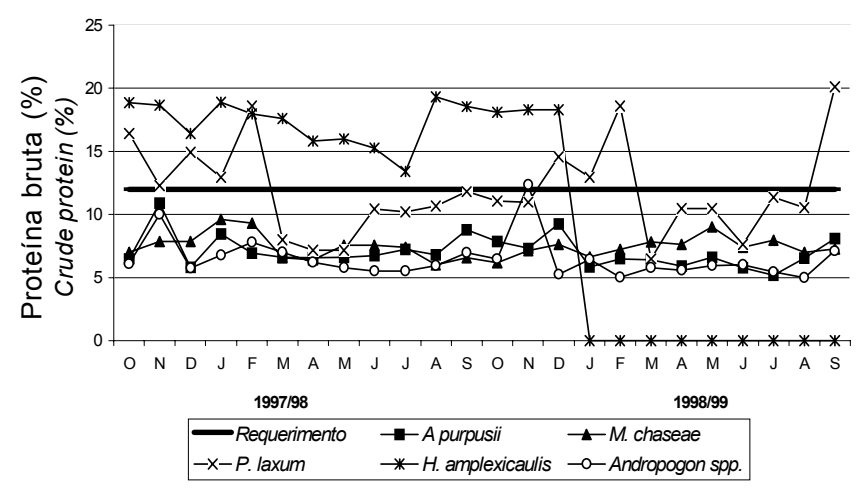

Figura 2 - Variação mensal no teor de proteína bruta das partes foliares selecionadas por bovinos das diversas espécies forrageiras, no período de outubro/97 a setembro/99 na sub-região da Nhecolândia, Pantanal.

Figure 2 - Monthly variation in the content of crude protein of leaf part selected by cattle of diverse forage species from October 1997 to September 1999, in the Nhecolândia sub-region, Pantanal. des de manutenção, porém, estiveram abaixo das reais necessidades reprodutivas.

Os valores mensais médios de FDA observados variaram de 36,35 a 45,84\% e os de FDN de 64,21 a $78,52 \%$. As médias de FDA estimadas foram mais baixas no período de outubro a março, enquanto a FDN apresentou médias mais baixas no ano de 1998/ 99, principalmente no período de julho a setembro (época seca), observados na Tabela 1. O teor médio mensal de lignina observado na dieta variou de 4,56 a $11,24 \%$, cujos valores estimados foram mais baixos no período de outubro a dezembro e os mais altos no período de abril a setembro. O conteúdo da parede celular pode diferir em função das diversas partes das plantas, famílias e espécies, bem como entre gramíneas de clima temperado e tropical e, de acordo com o estádio fenológico das plantas. Neste estudo, os valores mais altos encontrados de abril e setembro deve-se, principalmente, ao estádio fenológico das principais espécies consumidas, enquanto os teores mais altos encontrados durante o ano de 1998/99 provavelmente se deve à maior proporção de espécies não gramíneas na dieta (Santos et al., 2001c).

$\mathrm{Na}$ Figura 3 observa-se a variação mensal da digestibilidade da matéria orgânica (DMO) da pastagem durante os dois anos de estudo. Embora a equação de calibração tenha sido desenvolvida para uma população diferente da população estudada, os resultados pareceram confiáveis. Os valores de

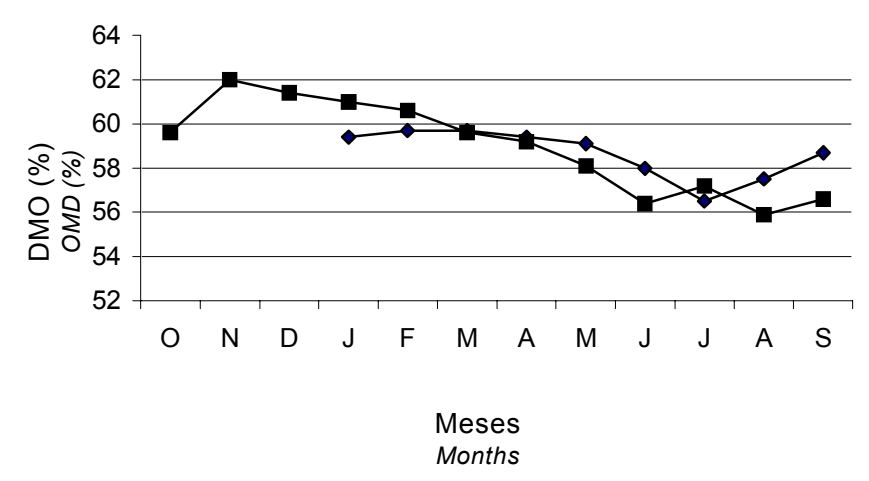

Figura 3 - Estimativa da digestibilidade da matéria orgânica (DMO) da dieta de bovinos mantidos em pastagem nativa na sub-região da Nhecolândia, Pantanal, durante dois anos hidrológicos.

Figure 3 - Organic matter digestibility (OMD) of diets of cattle grazing in rangelands in the Nhecolândia sub-region, Pantanal, during two hydrologyc years.

R. Bras. Zootec., v.31, n.4, p.1663-1673, 2002 
digestibilidade da dieta mostraram um aumento a partir de setembro, atingindo picos nos meses de novembro a janeiro, principalmente no ano hidrológico 1998/99, enquanto os valores mais baixos foram encontrados de maio a agosto, em ambos os anos estudados.

Deve ser considerado que o período préacasalamento do ano 1998/99 foi influenciado pela dieta dos animais no ano 1997/98, que teve uma proporção maior de espécies de gramíneas do ciclo C3 (H. amplexicaulis, $P$. laxum), geralmente mais digeríveis. No ano de 1998/99, também foi observado os valores de digestibilidade mais baixos, a partir do mês de maio. Portanto, em nível de produção animal, ao invés de ano hidrológico (outubro a setembro), muitos estudos têm considerado o ano pecuário, que corresponde ao período de junho a maio (Almeida, 1997; Abreu et al., 2000). O ano pecuário parece ser mais adequado na avaliação do desempenho animal, haja vista que durante o estudo, o período pré-acasalamento do ano hidrológico de 1998/99 (outubro a dezembro), que proporcionou uma dieta adequada aos animais, foi precedido de um período sem inundação e com distribuição normal de chuvas, que correspondeu ao ano hidrológico 1997/98. Assim, o ano pecuário sem inundação favoreceu o pastejo das áreas de baixadas, possibilitando o consumo de espécies forrageiras de melhor qualidade, o que refletiu na condição corporal e consequentemente, num melhor desempenho reprodutivo. Na Tabela 2 constam os conteúdos médios de PB, FDA, FDN e lignina das partes das espécies potencialmente consumidas por bovinos na área.

O valor alimentício das forrageiras de uma pastagem pode ser avaliado em termos de produção animal, preferencialmente em condições de pastejo e pelo consumo voluntário de energia líquida. Como nem sempre estas medidas são possíveis, a determinação da digestibilidade da matéria seca ou da matéria orgânica tem sido utilizada para expressar a energia disponível das forrageiras (Euclides, 1995). Este fato pode ser comprovado neste estudo através da alta correlação entre condição corporal e DMO (Tabela 3 ).

Na Tabela 3 também são apresentados os coeficientes de correlação entre os constituintes químicos da dieta, variáveis de comportamento de pastejo (tempo de pastejo e tempo de ruminação), DMO, nível de precipitação (PPT) e distância média diária percorrida. As correlações entre TR com DMO e PPT mostraram-se significativas $(\mathrm{P}<0,05)$, indicando

\footnotetext{
R. Bras. Zootec., v.31, n.4, p.1663-1673, 2002
}

associação positiva entre tempo de ruminação com a digestibilidade da dieta e associação negativa com LIG. Por sua vez, Rook \& Huckle (1996) não encontraram correlação entre variáveis de comportamento e variáveis meteorológicas. Uma explicação para os resultados encontrados se deve provavelmente ao efeito marcante das chuvas no Pantanal sobre as unidades de paisagem usadas para pastejo no ano de 1998/99, período no qual os animais em vez de caminharem, ficaram maior tempo ruminando nas áreas mais elevadas, como caronal e campo limpo (Santos et al., 2001a). A distância percorrida média diária foi de $4115 \mathrm{~m}$ e apresentou correlação negativa com digestibilidade. Dessa forma, os animais caminharam mais quando a digestibilidade da dieta foi baixa. Segundo Schmitt (1999), um indicativo prático da baixa disponibilidade e/ou da má qualidade da pastagem é a grande distância percorrida pelos animais. Houve correlação negativa da $\mathrm{PB}$ com todos os constituintes da parede celular (FDA, FDN e LIG).

Os escores de condição corporal foram significativamente diferentes entre os anos. Das variáveis analisadas apenas FDA e lignina da dieta tiveram influência significativa sobre o escore da condição corporal das vacas. Embora a digestibilidade da dieta não tenha influenciado significativamente o escore de condição corporal, observou-se que esta é altamente associada com condição corporal, principalmente pelo fato da lignina se associar negativamente com digestibilidade (Tabela 3). Estes resultados são similares aos encontrados por Ford et al. (1974); citados por Fahey \& Hussein (1999). No entanto, Holeckeck et al. (1982), consideram que lignina não é um preditor confiável da digestibilidade da matéria seca, pois a lignina de espécies forrageiras novas pode ser parcialmente digerível.

Estudos têm mostrado que vacas com boa condição corporal têm melhor desempenho reprodutivo (Barcellos \& Lobato, 1997). Neste estudo, as taxas de natalidade (TN) foram de 50 e $82 \%$ para os anos hidrológicos de 1997/98 e 1998/99, respectivamente. No ano de 1997/98, a TN esteve próxima da média tradicional no Pantanal, que é de 50-55\%. A TN mais alta encontrada no ano de 1998/99, provavelmente, deve-se à alta qualidade da dieta, especialmente antes da estação de monta, a partir de setembro, conforme mostra os dados de digestibilidade da dieta (Figura 3). No período de setembro a março de 1998/ 99, as vacas apresentaram escore corporal acima de cinco, indicando que esta condição corporal, durante 
Tabela 2 - Contéudos médios de proteína bruta (PB), fibra em detergente ácido (FDA), fibra em detergente neutro (FDN) e lignina (LIG) das partes das principais forrageiras selecionadas por bovinos no Pantanal da Nhecolândia

Table 2 - Mean contents of crude protein (CP), acid detergent fiber (ADF), neutral detergent acid (NDF) and lignin (LIG) of the main forage species parts consumed by cattle in the Nhecolândia sub-region, Pantanal

\begin{tabular}{|c|c|c|c|c|c|c|}
\hline $\begin{array}{l}\text { Espécies forrageiras, nome comum } \\
\text { Forage species, common name }\end{array}$ & $\begin{array}{l}\text { Famílias } \\
\text { Families }\end{array}$ & $\begin{array}{c}\text { Partes } \\
\text { consumidas }^{1} \\
\text { Consumed parts }\end{array}$ & $\begin{array}{l}\mathrm{PB} \\
C P\end{array}$ & $\begin{array}{l}\text { FDA } \\
A D F\end{array}$ & $\begin{array}{l}\text { FDN } \\
N D F\end{array}$ & $\begin{array}{l}\mathrm{LIG} \\
L I G\end{array}$ \\
\hline $\begin{array}{l}\text { Echinodorus paniculatus Mich., } \\
\text { chapéu-de-couro }\end{array}$ & Alismataceae & $\begin{array}{l}\mathrm{F} \text { e } \mathrm{H} \\
L \text { and } S\end{array}$ & 16,72 & 36,0 & 56,60 & 7,40 \\
\hline Annona dioica A. St.-Hil., arixicum & Annonaceae & $\begin{array}{l}\text { FB } \\
B L\end{array}$ & 10,45 & 48,44 & 64,53 & 22,28 \\
\hline Hancornia speciosa Gomez, mangaba & Apocynaceae & $\begin{array}{l}\mathrm{FB} \\
B L\end{array}$ & 6,04 & 33,81 & 45,08 & 23,12 \\
\hline Sheelea phalerata (Mart.) Bur., acuri & Arecaceae (Palmae) & $\begin{array}{l}\mathrm{FN} \\
Y L\end{array}$ & 10,38 & 49,37 & 77,91 & 16,92 \\
\hline Bidens gardneri Baker, picão & Asteraceae (Compositae) & $\begin{array}{l}\mathrm{F}, \mathrm{FB} \text { e I } \\
L, B L \text { and } I\end{array}$ & 8,21 & 32,8 & 40,92 & 18,01 \\
\hline Arrabidaea $\mathrm{sp}$ & Bignoniaceae & $\begin{array}{l}\text { FB } \\
B L\end{array}$ & 17,82 & 34,65 & 53,45 & 8,65 \\
\hline $\begin{array}{l}\text { Hymenaea stigonocarpa (Mart.) Hayne, } \\
\text { jatobá }\end{array}$ & Caesalpiniaceae & $\begin{array}{l}\mathrm{FN} \\
Y L\end{array}$ & 10,36 & 39,19 & 53,71 & 19,84 \\
\hline Cecropia pachystachya Trec., embaúba & Cecropiaceae & $\begin{array}{l}\mathrm{F} \\
L\end{array}$ & 12,65 & - & - & - \\
\hline $\begin{array}{l}\text { Cyperus haspan L. ssp. } \\
\text { juncoides (Lam.) Kük., cebolinha }\end{array}$ & Cyperaceae & $\begin{array}{l}\text { PPl } \\
T P\end{array}$ & 10,07 & 33,74 & 62,94 & 6,29 \\
\hline $\begin{array}{l}\text { Eleocharis acutangula (Roxb.) } \\
\text { Steud., cebolinha }\end{array}$ & Cyperaceae & $\begin{array}{l}2 / 3 \mathrm{~F} \\
2 / 3 L\end{array}$ & 11,61 & 42,66 & 64,07 & 6,40 \\
\hline $\begin{array}{l}\text { E. interstincta (Vahl) Roem. \& } \\
\text { Schult.,cebolinha }\end{array}$ & Cyperaceae & $\begin{array}{l}2 / 3 \mathrm{~F} \\
2 / 3 L\end{array}$ & 9,2 & 43,43 & 70,86 & 4,65 \\
\hline E. minima Kunth, lodo & Cyperaceae & $\begin{array}{l}2 / 3 \mathrm{~F} \\
2 / 3 L\end{array}$ & 9,94 & 42,22 & 69,64 & 6,80 \\
\hline Rynchospora tenuis Link, barba-de-bode & Cyperaceae & $\begin{array}{l}\text { PPl } \\
T P\end{array}$ & 6,24 & 49,63 & 75,22 & 6,98 \\
\hline $\begin{array}{l}\text { R. trispicata (Nees) Steud., } \\
\text { capim-navalha }\end{array}$ & Cyperaceae & $\begin{array}{l}\text { PPl } \\
T P\end{array}$ & 6,14 & 46,20 & 70,71 & 9,50 \\
\hline $\begin{array}{l}\text { Scleria melaleuca } \text { Rchb. } \\
\text { (S. pterota } \text { Presl), capim-navalha }\end{array}$ & Cyperaceae & $\begin{array}{l}2 / 3 \mathrm{~F} \\
2 / 3 L\end{array}$ & 16,59 & 35,41 & 65,99 & 5,47 \\
\hline Curatella americana L., lixeira & Dilleniaceae & $\begin{array}{l}\mathrm{FN} \text { e } \mathrm{FB} \\
Y L \text { and } B L\end{array}$ & 8,48 & 42,49 & 69,61 & 13,75 \\
\hline $\begin{array}{l}\text { Doliocarpus dentatus (Aubl.) Standl., } \\
\text { cipó-de-fogo }\end{array}$ & Dilleniaceae & $\begin{array}{l}\mathrm{FN} \text { e } \mathrm{FB} \\
Y L \text { and } B L\end{array}$ & 10,27 & 48,71 & 65,14 & 9,06 \\
\hline Alchornea discolor Poepp., uva-brava & Euphorbiaceae & $\begin{array}{l}\mathrm{FN} \\
Y L\end{array}$ & 14,94 & 40,26 & 54,86 & 17,3 \\
\hline $\begin{array}{l}\text { Caperonia castaneifolia (L.) A. St.-Hil., } \\
\text { erva-de-bicho-branca }\end{array}$ & Euphorbiaceae & $\begin{array}{l}\mathrm{F} \text { e } \mathrm{H} \\
L \text { and } S\end{array}$ & 17,83 & 24,85 & 37,08 & 3,49 \\
\hline $\begin{array}{l}\text { Euphorbia thymifolia L., } \\
\text { leite-de-nossa-senhora }\end{array}$ & Euphorbiaceae & $\begin{array}{l}\mathrm{F} \text { e } \mathrm{H} \\
L \text { and } S\end{array}$ & 13,84 & - & - & - \\
\hline Sebastiania hispida (Mart.) Pax, mercúrio & Euphorbiaceae & $\begin{array}{l}\mathrm{F} \\
L\end{array}$ & 10,87 & 19,46 & 23,06 & 4,77 \\
\hline $\begin{array}{l}\text { Aeschynomene fluminensis Vell., } \\
\text { cortiça }\end{array}$ & Leguminoseae/ Fabaceae & $\mathrm{F}$ & 17,75 & 32,96 & 66,31 & 10,93 \\
\hline Desmodium barbatum (L.) Benth & Leguminoseae/ Fabaceae & $\begin{array}{l}\mathrm{F} \\
L\end{array}$ & 16,9 & 38,50 & 57,96 & 12,29 \\
\hline Andropogon bicornis L., rabo-de-burro & Gramineae (Poaceae) & PF & 5,65 & 44,31 & 76,76 & 7,05 \\
\hline $\begin{array}{l}\text { A. hypogynus Hack., rabo-de-lobo, } \\
\text { capim-vermelho }\end{array}$ & Gramineae (Poaceae) & $\begin{array}{l}\mathrm{PF}, 2 / 3 \mathrm{FN} \\
T L \text { and } 2 / 3 Y L\end{array}$ & 6,42 & 46,49 & 80,72 & 7,11 \\
\hline $\begin{array}{l}\text { A. selloanus (Hack.) Hack., } \\
\text { rabo-de-carneiro }\end{array}$ & Gramineae (Poaceae) & $\begin{array}{l}2 / 3 \mathrm{~F} \\
2 / 3 L\end{array}$ & 5,0 & 46,52 & 80,83 & 5,35 \\
\hline $\begin{array}{l}\text { Axonopus paraguayensis Black, } \\
\text { capim-fino }\end{array}$ & Gramineae (Poaceae) & $\begin{array}{l}\mathrm{PF} \\
T L\end{array}$ & 5,36 & 44,38 & 81,6 & 7,18 \\
\hline A. purpusii (Mez) Chase, mimoso & Gramineae (Poaceae) & $\begin{array}{l}2 / 3 \mathrm{~F} / \mathrm{PN} \\
2 / 3 \mathrm{~L} / \mathrm{YP}\end{array}$ & 6,89 & 42,12 & 75,47 & 4,96 \\
\hline Digitaria ciliaris (Retz.) Koel., milhã & Gramineae (Poaceae) & $\begin{array}{l}\mathrm{F} \text { e } \mathrm{H} \\
L \text { and } S\end{array}$ & 9,03 & 42,46 & 72,65 & 5,86 \\
\hline $\begin{array}{l}\text { Eleusine indica (L.) Gaertn., } \\
\text { pé-de-galinha }\end{array}$ & Gramineae (Poaceae) & $\begin{array}{l}\mathrm{F} \\
L\end{array}$ & 16,32 & 44,55 & 67,58 & 9,15 \\
\hline $\begin{array}{l}\text { Elyonurus muticus (Spr.) Kunth, } \\
\text { capim-carona }\end{array}$ & Gramineae (Poaceae) & $\begin{array}{l}\text { PFQ } \\
T P B\end{array}$ & 10,88 & 33,90 & 72,45 & 4,26 \\
\hline Gymnopogon spicatus (Spreng.) & Gramineae (Poaceae) & PPl & 4,78 & 45,29 & 86,31 & 7,98 \\
\hline
\end{tabular}


Continuação da Tabela 1 ...

O. Kuntze, taquarinha

Hymenachne amplexicaulis (Rudge) Nees, Gramineae (Poaceae) campim-de-capivara

Ichnanthus procurrens (Nees)

Swallen, talo-roxo

Leersia hexandra Sw.,

grameiro, arrozinho

Luziola subintegra Swallen,

capim-arroz

Mesosetum chaseae Luces,

grama-do-cerrado

Panicum hirtum Lam., taquarinha

Panicum laxum Sw.,

grama-do-carandazal

Paspalidium paludivagum

(Hitch. \& Chase) Parodi, mimoso-de-talo

Paspalum plicatulum Michaux., felpudo

Setaria geniculata (Lam.) Beauv., mimoso-vermelho

Reimarochloa brasiliensis (Spr.)

Hitchc.,mimosinho

Sorgastrum setosum (Griseb.) Hitchc

Hydrolea spinosa L., amoroso

Hyptis brevipes (Poit.), hortelãzinha

Psittacanthus calyculatus (D.C.)

G. Don ,erva-de-passarinho

Banisteriopsis pubipetala (Juss.)

Catr.,cipó-de-pomba

Byrsonima orbignyana A. Juss., canjiqueira

Thalia geniculata L., caeté

Mouriri elliptica Mart., coroa-de-frade

Mimosa sp

Nymphaea gardneriana Planch., camalote-da-meia-noite

Pontederia parviflora Alexander, guapé

Diodia kuntzei K. Schum

Richardia grandiflora (Cham. \& Schltdl.)

Steud., bernarda

Tocoyena formosa (Cham. \& Schltdl.)

K. Schum., olho-de-boi

Bacopa sp.

Smilax fluminensis Steud.,

japecanga-folha-larga

Melochia simplex A. St.-Hil., malva

Waltheria albicans Turez, malva-branca

Vitex cymosa Bert., tarumã

Cissus erosa L. C. Rich., cipó-de-arraia-liso

Xyris savannensis Miq.

\begin{tabular}{|c|c|c|c|c|c|}
\hline Gramineae (Poaceae) & $\begin{array}{c}T P \\
\mathrm{~F} \text { e } \mathrm{H} \\
L \text { and } S\end{array}$ & 17,91 & 37,79 & 63,61 & 5,57 \\
\hline Gramineae (Poaceae) & $\begin{array}{c}\mathrm{F} \text { e } \mathrm{H} \\
L \text { and } S\end{array}$ & 8,4 & - & - & - \\
\hline Gramineae (Poaceae) & $\begin{array}{c}\mathrm{F} \text { e } \mathrm{H} \\
L \text { and } S\end{array}$ & 11,51 & 44,76 & 75,64 & 6,63 \\
\hline Gramineae (Poaceae) & $\begin{array}{l}\text { PF } \\
T L\end{array}$ & 4,0 & 46,52 & 82,32 & \\
\hline Gramineae (Poaceae) & $\begin{array}{c}\mathrm{F} \text { e } \mathrm{H} \\
L \text { and } S\end{array}$ & 7,46 & 40,88 & 76,83 & 6,0 \\
\hline Gramineae (Poaceae) & $\begin{array}{l}\text { PF } \\
T L\end{array}$ & 4,37 & 47,85 & 77,93 & 10 \\
\hline Gramineae (Poaceae) & $\begin{array}{l}\mathrm{PN} \text { e PPl } \\
Y P \text { and } T P\end{array}$ & 11,81 & 41,67 & 72,89 & \\
\hline Gramineae (Poaceae) & $\begin{array}{l}\mathrm{F} \text { e } \mathrm{H} \\
L \text { and } S\end{array}$ & 13,95 & 40,5 & 70,09 & \\
\hline Gramineae (Poaceae) & $\begin{array}{c}\text { PPl } \\
T P\end{array}$ & 8,59 & 44,19 & 77,41 & \\
\hline Gramineae (Poaceae) & $\begin{array}{l}\mathrm{FN} \\
Y L\end{array}$ & 11,91 & 35,41 & 70,87 & \\
\hline Gramineae (Poaceae) & $\begin{array}{l}2 / 3 \mathrm{Pl} \\
2 / 3 \mathrm{P}\end{array}$ & 11,28 & 36,70 & 66,40 & \\
\hline Gramineae (Poaceae) & $\begin{array}{l}\mathrm{PF} \\
T L\end{array}$ & 5,37 & 45,81 & 80,83 & \\
\hline Hydrophyllaceae & $\begin{array}{c}\mathrm{F} \text { e } \mathrm{H} \\
L \text { and } S\end{array}$ & 14,26 & 24,8 & 36,22 & \\
\hline Labiateae & $\begin{array}{c}\text { PPL } \\
T P\end{array}$ & 11,74 & 31,14 & 41,42 & 13,71 \\
\hline Loranthaceae & $\begin{array}{l}\mathrm{F} \\
L\end{array}$ & 5,58 & 38,72 & 42,55 & 16,4 \\
\hline Malpighiaceae & $\begin{array}{l}\text { FN } \\
\text { YL }\end{array}$ & 8,32 & 41,07 & 54,91 & 2 \\
\hline Malpighiaceae & FN e $\mathrm{P}$ & 9,73 & 44,67 & 67,17 & 18 \\
\hline Marantaceae & $\begin{array}{c}Y L \text { and } B L \\
\text { FN } \\
Y L\end{array}$ & 16,44 & 31,83 & 64,51 & 3,95 \\
\hline Melastomataceae & $\begin{array}{l}\mathrm{F} \\
L\end{array}$ & 8,25 & 44,32 & 52,42 & 10,71 \\
\hline guminoseae/Mimosaceae & $\begin{array}{l}\mathrm{F} \\
L\end{array}$ & 12,05 & 28,58 & 52,42 & 10,71 \\
\hline Nymphaeaceae & $\begin{array}{l}\mathrm{F} \\
L\end{array}$ & 16,03 & 23,46 & 32,79 & \\
\hline Pontederiaceae & $\begin{array}{l}\text { PN } \\
Y P\end{array}$ & 9,2 & 37,0 & 67,91 & \\
\hline Rubiaceae & $\begin{array}{c}\mathrm{F} \text { e } \mathrm{H} \\
L \text { and } S\end{array}$ & 8,84 & 32,94 & 47,2 & 11,14 \\
\hline Rubiaceae & $\begin{array}{c}\mathrm{F} \text { e } \mathrm{H} \\
L \text { and } S\end{array}$ & 8,26 & 39,48 & 44,35 & 10,36 \\
\hline Rubiaceae & $\begin{array}{l}\mathrm{F} \\
L\end{array}$ & 9,1 & 71,2 & 82,62 & - \\
\hline Scrophulariaceae & F & 11,36 & 32,79 & 47,27 & \\
\hline Smilacaceae & $\mathrm{F}$ & 12,12 & 44,18 & 62,42 & 4,87 \\
\hline Sterculiaceae & $\begin{array}{l}\text { PN } \\
Y P\end{array}$ & 8,68 & 35,24 & 43,71 & 18,23 \\
\hline Sterculiaceae & $\begin{array}{l}\mathrm{F} \\
L\end{array}$ & 15,12 & 37,17 & 55,59 & 10,41 \\
\hline Verbebaceae & $\begin{array}{l}\mathrm{FN} \\
Y L\end{array}$ & 15,26 & 51,78 & 72,61 & \\
\hline Vitaceae & $\begin{array}{l}\text { FN } \\
Y L\end{array}$ & 13,12 & 48,54 & 59,52 & \\
\hline Xyridaceae & $\begin{array}{l}2 / 3 \mathrm{Pl} \\
2 / 3 \mathrm{P}\end{array}$ & 8,09 & 38,21 & 73,1 & \\
\hline
\end{tabular}

$\mathrm{F}=$ folhas; $\mathrm{FB}=$ folhas em brotação; $\mathrm{FN}=$ folhas novas; $2 / 3 \mathrm{~F}=2 / 3$ das folhas; $\mathrm{H}=$ hastes; $\mathrm{I}=$ inflorescência; $P F=$ ponta das folhas; $P F Q=$ ponta das folhas pós queima; $\mathrm{PN}=$ plantas novas; $\mathrm{PPI}=$ ponta das plantas; $2 / 3 \mathrm{PI}=2 / 3$ das plantas.

$L=$ leaves; $B L=$ budding leaves; $Y L=$ young leaves; $2 / 3 L=2 / 3$ of leaves; $S=$ stem; $I=$ inflorescence; $T L=$ top of leaves; $T P B=$ top of plants after burning; $Y P=$ young plants; $T P=$ top of plants; $2 / 3 P=2 / 3$ of plants.

R. Bras. Zootec., v.31, n.4, p.1663-1673, 2002 
o período de estação de monta e grande parte do período de lactação, pareceu adequada pois não comprometeu a taxa de fertilidade. No entanto, os índices de TN encontrados neste estudo poderiam ter sido melhores, haja vista que os bezerros foram mantidos com as vacas até a desmama natural, com aproximadamente 10-12 meses de idade, impedindo que a vaca entrasse em cio mais rapidamente. Segundo Almeida (1997), a desmama aos seis meses de idade proporcionou aumento de 10 a $15 \%$ no índice de natalidade. Já a desmama aos quatro meses aumenta a taxa de natalidade, porém, os bezerros devem ser recriados em pastagem cultivada até oito meses, pois a recria em pastagem nativa elevou a mortalidade para $16 \%$ após a desmama.

Concordando com as sugestões de Wright (1998), no Pantanal, as restrições nutricionais causadas pela estacionalidade da produção de pastagens podem ser reduzidas de duas maneiras: escolha de espécies e/ou raças adaptadas ao local e adoção de uma série de estratégias para melhorar o nível de nutrição animal. Porém, em regiões como o Pantanal, a implantação de novas técnicas tem limitações e deve ser feita com cautela, de modo que o meio ambiente não seja prejudicado.

Um dos problemas mais comuns de nutrição de grandes herbívoros criados extensivamente é a deficiência de proteína e energia. Nas épocas de restrição alimentar, os animais sobrevivem deslocando reservas corporais de energia e proteína, que por sua vez foram armazenadas numa época de abundância de alimentos (Demment \& Van Soest, 1985). Nos períodos de escassez alimentar, as vacas prenhes ou em lactação necessitam mobilizar reservas corporais de energia e proteína para sustentar o crescimento fetal e produção de leite, respectivamente. O grau no qual isto ocorre depende do genótipo do animal. Vale salientar que, dentro do rebanho em estudo, foram observadas algumas vacas que mantiveram o escore da condição corporal entre 5 e 6 , produzindo um bezerro por ano durante o período de estudo. A seleção de vacas que mantém o escore corporal acima de 5 e reproduzem todo ano, independente da estacionalidade das pastagens, seria uma das estratégias para aumentar a produtividade no Pantanal.

Tabela 3 - Correlações entre variáveis de qualidade da dieta e climáticas (precipitação) com variáveis de comportamento de pastejo, condição corporal e distância percorrida por bovinos ${ }^{1}$

Table 3 - Correlations between diet quality and precipitation variables and grazing behaviour variables, body condition and distance covered by cattle 1

\begin{tabular}{|c|c|c|c|c|c|c|}
\hline Variáveis & PB & FDA & FDN & LIG & DMO & $\mathrm{ppt}$ \\
\hline Variables & $C P$ & $A D F$ & $N D F$ & $L I G$ & $O M D$ & ppt \\
\hline $\begin{array}{l}\mathrm{TP} \\
G T\end{array}$ & $0,12 \mathrm{~ns}$ & $0,20 \mathrm{~ns}$ & $-0,13 \mathrm{~ns}$ & $0,36 \mathrm{~ns}$ & $-0,14 \mathrm{~ns}$ & $-0,27 \mathrm{~ns}$ \\
\hline $\begin{array}{l}\text { TR } \\
R T\end{array}$ & $-0,03 \mathrm{~ns}$ & $-0,14 \mathrm{~ns}$ & $0,29 \mathrm{~ns}$ & $-0,66^{*}$ & $0,58^{*}$ & $0,56^{*}$ \\
\hline $\begin{array}{l}C C \\
B C\end{array}$ & $-0,13 \mathrm{~ns}$ & $0,05 \mathrm{~ns}$ & $-0,26 \mathrm{~ns}$ & $-0,14 \mathrm{~ns}$ & $0,70^{*}$ & $0,36 \mathrm{~ns}$ \\
\hline $\begin{array}{l}\text { DIST } \\
D D\end{array}$ & $0,11 \mathrm{~ns}$ & $-0,01 \mathrm{~ns}$ & $-0,01 \mathrm{~ns}$ & $0,26 \mathrm{~ns}$ & $-0,77^{*}$ & $-0,34 n s$ \\
\hline $\begin{array}{l}\mathrm{PB} \\
C P\end{array}$ & & $-0,62 *$ & $-0,45^{*}$ & $-0,44^{*}$ & $0,28 \mathrm{~ns}$ & $0,36 \mathrm{~ns}$ \\
\hline $\begin{array}{l}\text { FDA } \\
A D F\end{array}$ & & & $0,65^{*}$ & $0,60^{*}$ & $-0,28 \mathrm{~ns}$ & $-0,12 \mathrm{~ns}$ \\
\hline $\begin{array}{l}\text { FDN } \\
N D F\end{array}$ & & & & $0,09 \mathrm{~ns}$ & $-0,07 \mathrm{~ns}$ & $0,12 \mathrm{~ns}$ \\
\hline $\begin{array}{l}\text { LIG } \\
L I G\end{array}$ & & & & & $-0,78^{*}$ & $-0,61 *$ \\
\hline DMO & & & & & & $0,74^{*}$ \\
\hline
\end{tabular}

* $\mathrm{P}<0,05$.

${ }^{1} \mathrm{~PB}=$ proteína bruta; $\mathrm{FDA}=$ fibra em detergente neutro; FDN = fibra em detergente ácido; $\mathrm{LIG}$ = lignina; $\mathrm{DMO}=$ digestibilidade da matéria orgânica; $\mathrm{PPT}=$ nível de precipitação mensal; $\mathrm{TP}=$ tempo de pastejo; $\mathrm{TR}=$ tempo de ruminação; $\mathrm{CC}$ = condição corporal; DIST = distância diária percorrida.

${ }_{1} \mathrm{CP}=$ crude protein; $A D F=$ acid detergent fiber; $N D F=$ neutral detergent fiber; $L I G=$ lignin; $D M O=$ organic matter digestibility; ppt = rainfall; $G T=$ grazing time; $R T=$ rumination time; $B C=$ body condition; $D D=$ daily distance.

R. Bras. Zootec., v.31, n.4, p.1663-1673, 2002 
Apesar da estimativa do valor nutritivo das forrageiras pelo valor de constituintes químicos isolados não ser adequada, pois outros fatores podem ser limitantes, tais como toxicidade, deficiência de minerais, fatores antinutricionais, bem como a natureza complexa desses componentes químicos no processo de digestão (Euclides, 1995), neste estudo os constituintes analisados parecem ter revelado o valor nutritivo da dieta. Embora tenha sido fixado o valor de $12 \%$ de PB para a obtenção de máxima produtividade, o teor de cerca de $10 \%$ encontrado no ano de 1998/99 associado com valores de $40,20 \%$ de FDA, $71 \%$ de FDN, $6,0 \%$ de lignina e a alta digestibilidade das forrageiras consumidas pareceu suficiente para manter as vacas numa boa condição corporal (escore acima de 5) no período pré-acasalamento, o que possibilitou um bom desempenho reprodutivo. Conforme Emmas (1991), a composição da dieta que o animal necessita é aquela no qual eles mostram um desempenho adequado. Portanto, as partes das plantas selecionadas por bovinos que possuem constituição química próxima aos valores citados parecem ser adequadas para os bovinos de cria no Pantanal durante o período de maiores exigências que correspondem ao período de préacasalamento e de lactação. Estudos adicionais são necessários para identificar outros constituintes químicos da dieta selecionada, tais como os minerais.

\section{Conclusões}

A qualidade da dieta selecionada por bovinos foi influenciada pela interação época $x$ ano, dependente especialmente da intensidade e distribuição da precipitação anual, que causa maior ou menor presença de água nas unidades de paisagem mais baixas, onde ocorrem as espécies forrageiras hidrófilas e/ou C3, geralmente de melhor qualidade, tais como H. amplexicaulis e P. laxum.

A dieta selecionada por bovinos apresentou menor valor nutritivo no período de abril a junho, em ambos os anos estudados. Portanto, na área estudada, este é o principal período de restrição alimentar.

Em anos com distribuição regular das chuvas, as vacas mantidas em pastagem nativa, conseguem obter uma dieta adequada e manter uma boa condição corporal (escore acima de 5) no período préacasalamento (outubro a dezembro), o que possibilita um bom desempenho reprodutivo.

\section{Agradecimento}

A João Batista Garcia, pela dedicação intensiva na execução deste trabalho. Ao técnico Ernande Ravaglia, aos estagiários Juliana, Anderson e Átila e aos motoristas, pelo auxílio nos trabalhos de campo. À equipe do laboratório de análises químicas. À Regina Célia Rachel dos Santos, que colaborou na confecção das figuras. Por fim, ao apoio financeiro da FUNDECT (Fundação de Apoio e de Desenvolvimento do Ensino, Ciência e Tecnologia) de MS, ao PRODETAB e ao CNPq, pela bolsa concedida.

\section{Literatura Citada}

ALMEIDA, I.L. Manejo reprodutivo: desmama e estação de monta. In: EMBRAPA. Centro de Pesquisa Agropecuária do Pantanal (Corumbá, MS). Tecnologias e informações para a pecuária de corte no Pantanal. Corumbá: EMBRAPA-CPAP. 1997. p.77-83.

ABREU, U.G.P.; CHALITA, L.V.A.S.; MORAES, A.S. et al. Introdução de tecnologias no sistema de produção de bovino de corte no Pantanal, sub-região da Nhecolândia, MS. Corumbá: Embrapa Pantanal, 2000. 37p. (Circular Técnica, 25).

BARCELLOS, J.O., LOBATO, J.F.P. Desempenho reprodutivo de vacas primíparas Hereford e mestiças Nelore-Hereford com estação de parição e monta no outono/inverno ou primavera/verão. 1. Taxa de prenhez. Revista da Sociedade Brasileira de Zootecnia, v.26, n.5, p.976-985, 1997.

DEMMENT, M.W.; Van SOEST, P.J. A nutritional explanation for body-size patterns of ruminant and nonruminant herbivores. The American Naturalist, v.125, n.5, p.641672, 1985.

DUNCAN, P. Determinants of the use of habitat by horses in a mediterranean wetland. Journal of Animal Ecology, v.52, p.93-109, 1983.

EMMANS, G.C. Diet selection by animals: theory and experimental design. In: PROCEEDINGS OF THE NUTRITION SOCIETY, Strathclyde, 1990, v.50, p.59-64, 1991.

EUCLIDES, V.P.B. Valor alimentício de espécies forrageiras do gênero Panicum. In: SIMPÓSIO SOBRE MANEJO DA PASTAGEM, 12., Piracicaba, 1995. Anais... Piracicaba: Fundação de Estudos Agrários "Luiz de Queiroz", 1995. p.245-273.

FAHEY, G.C.; HUSSEIN, H.S. Forty years of forage quality research: accomplishments and impact from na animal nutrition perspective. Crop Science, v.39, p.4-12, 1999.

HOLECHEK, J.L.; VAVRA, M.; PIEPER, R.D. Methods for determining the nutritive quality of range ruminant diets: a review. Journal of Animal Science, v. 54, n.2, p.363-376, 1982 .

LIMA, J.A.; NASCIMENTO Jr., D.; QUEIROZ, A.C. et al. Seletividade por bovinos em pastagem natural. 2. Valor nutritivo. Revista da Sociedade Brasileira de Zootecnia, v.27, n.3, p.444-452, 1998.

McINNIS, M.L.; VAVRA, M. Dietary relationships among feral horses, cattle, and pronghorn in Southeastern Oregon. Journal of Range Management, v.40, n.1, p.60-66, 1987. 
NiChOlson, M.J.; BUtTerworTh, M.H. A guide to condition scoring of Zebu cattle. Addis Ababa: International Livestock Centre for Africa, 1985.

O'REAGAIN, P.J.; SCHWARTZ, J. Dietary selection and foraging strategies of animals on rangeland. Coping with spatial and temporal variability. In: INTERNATIONAL SYMPOSIUM ON THE NUTRITION OF HERBIVORES, 4., 1995, Paris. Proceedings... Paris: INRA, 1995. p.407-423.

POTT, A. Pastagens nativas. In: EMBRAPA. Centro de Pesquisa Agropecuária do Pantanal (Corumbá, MS). Tecnologias e informações para a pecuária de corte no Pantanal. Corumbá: EMBRAPA-CPAP. 1997. 161p.

ROOK, A.J.; HUCKLE, C.A. Sources of variation in the grazing behaviour of dairy cows. Journal of Agricultural Science, v.126, p.227-233, 1996.

SANCHES, L.J.T.; NASCIMENTO Jr., D.; DIOGO, M.S. et al. Composição química da forragem disponível versus dieta de bovinos em pastagem natural. Revista da Sociedade Brasileira de Zootecnia, v.22, n.5, p.852-861, 1993.

SANTOS, S.A.; COSTA, C.; CHALITA, L.V.A.S. et al. Grazing behavior and activity patterns by free-grazing cattle in the Pantanal region. In: INTERNATIONAL GRASSLAND CONGRESS, 19., 2001, São Pedro, SP. Proceedings.. Piracicaba: Fundação de Estudos Agrários “Luis de Queiroz”, 2001a. p.297-298.

SANTOS, S.A.; COSTA, C.; CRISPIM, S.M.A. et al. Seleção das fitofisionomias da sub-região da Nhecolândia, Pantanal, por bovinos. In: SIMPÓSIO SOBRE RECURSOS NATURAIS E SÓCIO-ECONÔMICOS DO PANTANAL, 3., 2000, Corumbá, MS. Os desafios do novo milênio. Anais... Corumbá: Embrapa Pantanal, 2001b (CD ROM).

SANTOS, S.A.; COSTA, C.; SOUZA, G.S. et al. Identificação da composição botânica da dieta de bovinos em pastagem nativa na sub-região da Nhecolândia, Pantanal. Revista da Sociedade Brasileira de Zootecnia, v.31, n.4., p.1648-1662, 2002.
SAS INSTITUTE. System for Microsoft windows, Release 6.12, Cary: 1999. 1CD ROM.

SCHMITT, A.L. O comportamento animal como um instrumento de otimização de manejo e promoção do bem-estar do animal. Boletim Agroecológico, v.1, p.7, 1999.

STUTH, J.W.; KAPES, E.D.; LYONS, R.K. Use of Near Infrared spectroscopy to assess nutritional status of cattle diets on rangeland. In: INTERNATIONAL GRASSLAND CONGRESS, 17., 1989, Palmerston North, New Zealand. Proceedings.....New Zealand: New Zealand Grassland Association/New Zealand Society of Animal Production/ New Zealand/Australian: Tropical Grasslands Society of Australian/Australian Society of Animal Production Queensland Branch, 1993. v.2, p.889-990.

ULYATT, M.J., McNABB, W.C. Can protein utilisation from pasture be improved? In: REUNIÃO ANUAL SOCIEDADE BRASILEIRA DE ZOOTECNIA, 36., 1999, Porto Alegre. Anais...Porto Alegre: Sociedade Brasileira de Zootecnia, 1999. p.67-77.

Van SOEST, P.J. Development of a comprehensive system of feed analyses and its application to forages. Journal of Animal Science, v.26, n.1, p.119-128, 1967.

VERCOE, J.E. Pastures for prosperity. 5. The role of animal science. Tropical Grasslands, v.30, p.58-72, 1996.

WRIGHT, I.A. Identifying biological consstraints acting on livestock systems in marginal areas. In: LIVESTOCK SYSTEMS IN EUROPEAN RURAL DEVELOPMENT, 1., 1997, Nafplio. Proceedings... Scotland: LSIRD, 1998. p.11-18.

Recebido em: 28/08/01 Aceito em: 11/01/02 